\title{
The Agglomeration Characteristics of Blue Economic Zone of Shandong Peninsula
}

\author{
Fuhui Jing ${ }^{1, a}$, Lina Chang ${ }^{2, b}$, Hong Wang ${ }^{3, \mathrm{c}}$ \\ ${ }^{1}$ Qingdao Huanghai University, Qingdao, Shandong, China \\ ${ }^{2}$ Qingdao Huanghai University, Qingdao, Shandong, China \\ ${ }^{3}$ Qingdao Huanghai University, Qingdao, Shandong, China \\ a864352776@qq.com bchanglina1111@163.com \\ cwh201209@163.com
}

Keywords: Shandong Peninsula Blue Economic Zone; Spatial Agglomeration; Spatial Economic Ties

Abstract: This paper studies the spatial agglomeration of Shandong Peninsula Blue Economic Zone mainly through global Moran index and spatial economic ties index, then analyzes the Agglomeration and urban economic ties, finally puts forward the corresponding policy recommendations as a reference. J.T.Hu general secretary of the study of Shandong in Shandong for the future of social and economic development to make a clear strategic positioning. It has brought a new opportunity for the economic development of Shandong Peninsula.

Material to a core concentration is the basic phenomenon of the development of things. The objective existence of agglomeration in spatial economic activities, Moderate concentration can produce spatial agglomeration effect[1].The agglomeration of factors and economic activities in the regional space is the fundamental cause of the regional production, fundamental driving force for regional development. April 2009, J.T.Hu general secretary of the study of Shandong in Shandong for the future of social and economic development to make a clear strategic positioning. It has brought a new opportunity for the economic development of Shandong Peninsula. Peninsula Blue Economic Zone has become the breakthrough point of the development of modern marine economy in Shandong. But this research shows that, Shandong Peninsula Blue Economic Area of the overall weak, showing the scale of the expansion of the degradation, structural differentiation, the weakening of the radiation trend[2].

The article considers the spatial agglomeration of the blue economic zone of Shandong peninsula is of great significance to enhance the competitiveness of the economic zone, optimize the industrial structure, to give full play to the advantages of all over the world has important significance. The study found that the theory and empirical research of spatial agglomeration of foreign countries is fruitful. Location theory has universal applicability; therefore, it has a high reference value to the economic space on the regional level; domestic and foreign scholars have made a more reasonable explanation for the development of regional economy. The new economic geography school economists began to incorporate "geographical space" in western mainstream economics analysis framework. But the model of location theory only explains why the economy will lead to the gathering, rather than explain the economy itself; [3] Whether the spatial distance between the regions is affected by the interaction between the region and the spatial problem, the theory of regional economic spatial structure is not given; the new economic geography model assumption to relax, but still appears simple, rigid. Many empirical model provides the tools for quantitative study, widely should be used in the study of regional economy. The research of regional economy in China is concentrated on the empirical analysis and the specific planning of the research level, fundamental research to regional economy is absent. Most of the applied models 
are from foreign models, there are a lot of research on our country's regional economic development provided to draw lessons from[4].

\section{Second, the empirical analysis}

1.The sample selection and data sources

Based on the seven cities of Shandong peninsula as samples, Sample interval of 2010 2014.Data from the network, the National Bureau of Statistics website, Shandong province and the city statistical yearbook, data processing and analysis using SPSS13.0, to verify this agglomeration situation of Shandong Peninsula.

2. Model selection

(1)Global Moran index.

$$
\operatorname{Moran}^{\prime} \mathrm{I}=\frac{\sum_{\mathrm{i}=1}^{\mathrm{n}} \sum_{\mathrm{i}=1}^{\mathrm{n}} \mathrm{W}_{\mathrm{ij}}\left(\mathrm{Y}_{\mathrm{i}}-\overline{\mathrm{Y}}\right)\left(\mathrm{Y}_{\mathrm{j}}-\overline{\mathrm{Y}}\right)}{\operatorname{SS} \sum_{\mathrm{i}=1}^{\mathrm{n}} \sum_{\mathrm{j}=1}^{\mathrm{n}} \mathrm{W}_{\mathrm{ij}}}
$$

Global spatial autocorrelation in the spatial characteristics of the blue economic region of Shandong peninsula, shows that GDP per capita of the area $\mathrm{I}$, the total number $\mathrm{n}$ for the region, space weight matrix for the adjacent relation of each space; $=0$ the total number of $\mathrm{I}$ and $\mathrm{j}$ is adjacent to; is not adjacent. Moran, 'I value range $(1,1)$, if the value is positive economic zone was a positive correlation, the economy is high or low concentration, the greater the numerical effect more strong; if Moran I is negative, the economic scale Shandong economic zone has negative spatial correlation, showed low or high concentration, the smaller the value effect is strong; when Moran, the I value is 0 , then the city economy is independent random distribution, there is no spatial autocorrelation.

(2)The spatial economic relation index is defined by Wang Hongxia's model:

$$
\mathrm{L}=\mathrm{K}_{\mathrm{j}} * \frac{\sqrt[2]{\mathrm{V}_{\mathrm{i}} \mathrm{P}_{\mathrm{i}}}}{\mathrm{D}_{\mathrm{ij}} \mathrm{D}_{\mathrm{ij}}} \quad \mathrm{K}_{\mathrm{j}}=\frac{1}{3}\left(\frac{\mathrm{V}_{\mathrm{i}}^{\prime}}{\mathrm{V}_{\mathrm{j}}}+\frac{\mathrm{P}_{\mathrm{i}}^{\prime}}{\mathrm{P}_{\mathrm{j}}}+\frac{\mathrm{T}_{\mathrm{i}}}{\mathrm{T}}\right)
$$

Among them, $\mathrm{Pi}$ and $\mathrm{Vi}, \mathrm{Pj}$ and $\mathrm{Vj}$ for one year, $\mathrm{i}$ and $\mathrm{j}$ city population and GDP, Linear distance $D_{i j}$ into two city, $K_{j}$ for gravity coefficient, $P_{j}$, and $V_{j}$ non-agricultural population and non-agricultural production value respectively, $\mathrm{T}_{\mathrm{j}}$ for $\mathrm{j}$ city and I contact the total value of all the traffic facilities, traffic facilities scores were 2.0 for railway, highway 1.5 and shipping 1.0, $\mathrm{T}$ represents the entire transportation scores. The index set for index selection and score[5].

\section{The empirical results}

(1)The empirical results global Moran index

Table 1 Global Moran index of the blue economic zone of Shandong Peninsula

\begin{tabular}{|l|l|l|l|l|l|l|}
\hline Years & 2010 & 2011 & 2012 & 2013 & 2014 & 2015 \\
\hline $\begin{array}{l}\text { Moran index for } \\
\text { the whole years }\end{array}$ & -0.4458 & -0.4464 & -0.4478 & -0.4564 & -0.4578 & -0.464 \\
\hline
\end{tabular}

Shandong Peninsula Blue Economic Zone of the global Moran index, the global Moran index showed a downward trend, which showed that the trend of this kind of high or low or high concentration tended to be obvious, but after entering in 2014, basically stable. The results show 
that, Shandong Peninsula Blue Economic Zone Development in the existence of spatial autocorrelation, that is, the economic development of the city around, surrounded by a less developed city, at the same time, the economy is less developed cities around the more developed[6].

(2) The empirical results spatial economic ties index

Table 2 Space of the cities in Shandong Province Economic index in 2010

\begin{tabular}{|l|l|l|l|l|l|l|l|}
\hline 2010 & Qingdao's & Dongying's & Yanta’s & Weifang's & Weihai’s & Rizhao’s & Binzhou's \\
\hline Qingdao & ---- & 23.5648 & 85.0901 & 164.4844 & 23.6144 & 75.7456 & 14.0457 \\
\hline Dongying & 25.8677 & ---- & 14.9281 & 107.4346 & 4.0353 & 4.6908 & 77.0147 \\
\hline Yanta & 92.6645 & 14.8097 & ---- & 47.4808 & 267.345 & 8.4520 & 8.1308 \\
\hline Weifang & 175.5140 & 104.4329 & 47.4808 & ------- & 12.1214 & 30.6394 & 45.2558 \\
\hline Weihai & 25.5738 & 4.0033 & 265.861 & 12.3022 & ----- & 2.6641 & 2.1410 \\
\hline Rizhao & 88.5126 & 4.9934 & 9.0693 & 33.5538 & 2.8747 & ------ & 4.8233 \\
\hline Binzhou & 20.8092 & 103.9420 & 11.0615 & 62.8345 & 2.9290 & 4.6509 & ------- \\
\hline
\end{tabular}

Table 3 Space of the cities in Shandong Province Economic index in 2014

\begin{tabular}{|l|l|l|l|l|l|l|l|}
\hline 2014 & Qingdao's & Dongying's & Yantai’s & Weifang's & Weihai’s & Rizhao's & Binzhou's \\
\hline Qingdao & ---- & 33.6481 & 102.9010 & 164.4844 & 52.6441 & 103.756 & 46.4517 \\
\hline Dongying & 46.6787 & ---- & 54.2981 & 207.3446 & 24.3530 & 18.9086 & 127.1417 \\
\hline Yantai & 125.6456 & 14.8097 & ---- & 87.8408 & 412.304 & 24.4652 & 33.1038 \\
\hline Weifang & 265.1450 & 197.4529 & 107.4880 & ------- & 33.2114 & 60.6094 & 89.2558 \\
\hline Weihai & 75.7358 & 34.0133 & 379.9818 & 32.3202 & ----- & 12.6341 & 24.4110 \\
\hline Rizhao & 167.3526 & 14.6934 & 17.1683 & 59.0528 & 6.7747 & ------- & 9.2823 \\
\hline Binzhou & 48.8192 & 153.9020 & 41.625 & 92.9545 & 13.9190 & 14.6509 & ------- \\
\hline
\end{tabular}

The greater the spatial economic linkage index of the cities, the more closely related to the interaction 2010 and 2014 years in the Shandong Peninsula Blue Economic area of the city's spatial economic linkage index can be seen, the adjacent cities are closely linked and constantly enhanced. In Weifang, for example, it borders with Sunshine and Dongying, 2010, 2014, and the space of both economic ties index respectively30.6394,104.4329 and 50.6094,164.4529.The study found that the weifang and municipal space economic index is higher, the main reason is located right in the middle of Shandong Weifang, basic and peninsula bordering on other cities. Apart from the above, Qingdao and the city's economic ties more closely, strengthening the core position. Followed by Yantai, it and the city's spatial economic linkage index also increased.

Can be seen by comparing the Shandong Peninsula Blue Economic Zone cities closer economic ties, concentration increased. From and the space of Qingdao economic ties, Rizhao, Binzhou, and Weifang is growing the fastest growth rate in more than 90\%.Rizhao,Weifang and Qingdao border, the economy is closely linked. Qingdao, the weakest link with Binzhou, the economic linkage index growth is also very fast, Qingdao and the space of municipal economic ties to strengthen. From Weihai's spatial economic ties, Weihai's driving and radiation role in strengthening.

Empirical results from, the global Moran index, in 2014, the Shandong Peninsula Blue Economic Zone is still basically height gather the high or low status, Qingdao's core role is not prominent. Qingdao is the main reason for the Shandong Peninsula blue economic area, the central area of the peninsula, Shandong and even the the Yellow River river basin area, but the development of urban areas in Qingdao is too scattered, the lack of orderly sequence size. The distribution of the small town in the urban construction of Yantai is too concentrated, and there is no problem of producing range and so on. The distribution of the small town in the urban 
construction of Yantai is too concentrated, and there is no problem of producing range and so on. For other cities in the Economic Zone, Dongying has a large dependence on the resources, the position of the first order, the size of the first division, is not conducive to the overall advantages of regional cooperation. Weihai radiation hinterland ability is limited, the main city area. Qingdao and Linyi by the two major cities of, the size of the structure of a clear fault. Weifang between Jinan and Qingdao, the development of limited. In addition, although the Shandong Peninsula Blue Economic Zone Construction of the park but blossom everywhere, agglomeration and radiation deficiency. Investigate its reason: first, the Development Zone, the construction of the park in the presence of the phenomenon of blindly follow the trend; second, the construction of the Development Zone, not a complete industrial chain, the district can not coordinate with each other, complementary advantages. Third, the park planning and implementation of the lack of uniform standards of the park level is unclear, the division of unknown.

\section{Third, policy recommendations}

(1) Shandong Peninsula Economic Zone to strengthen the full range of docking with the surrounding cities, in accordance with the principle of dislocation competition, complementary advantages, support the advantages of industry and key enterprises, continue to grow and develop their own, and other urban agglomeration division of labor and positive interaction.

(2)W eihai, Qingdao to play a central role in strengthening economic cooperation and technological exchanges between other cities, the formation of regional linkage development. At the same time, strengthen the protection of ecological environment, realize the sustainable development of Blue Economy; break through the key technology of marine industry development, implement the project driven strategy.

(3)Focus on enhancing the maritime silk road construction, accelerate the construction of coastal economic development zone, industrial park, introducing and breeding production industry leading, supporting the backbone, advantage of enterprise scale, bigger and stronger, to promote regional industry, radiating the whole economic area.

(4) Expand opening to the outside world, in order to adhere to the "scale, speed and efficiency of paying equal attention to, industrial investment and industrial upgrading in parallel, the development and protection of resources, capital, technology, talents, famous brand and lead" principle, the surrounding edge industry investment promotion and capital introduction.

\section{Acknowledgments}

Colleges and Universities Humanities and Social Science Research Project in Shandong Province ( Project Number: J15WB70);Financed by the Fund of International Training Plan for Excellent You nger Teachers in Colleges and Universities of Shandong Province.

University-enterprise Cooperation Project of Qingdao Huanghai University

\section{References}

[1]X.Geng. Analysis of the Radiation Effect of Shanghai Free Trade Zone in Suzhou[J]. Intelligence. 2014(15)(In Chinese)

[2]F.F.Chen. The Agglomeration and Radiation Effect Analysis of Metropolitan Area

Development Research based on [D]. University Of Agriculture and Forestry In Fujian 2013 (In Chinese)

[3]Z.G.Ren. Qingdao City Blue Economic Zone Construction Advantage Analysis and Strategic Conception [J]. Qingdao municipal Party School of the Chinese Communist Party of 
Qingdao. 2011(02)(In Chinese)

[4] Bo Liu. Huaihai Economic Zone -- a Case Study of Lianyungang Economic Interaction [J]. Land and natural resources. 2010(05)(In Chinese)

[5] Ch.H Cai .Research on the Countermeasures of industrial cluster and urbanization development in Hebei Province [D]. Agricultural University Of Hebei .2010(In Chinese)

[6] M.Z Zhang. Spatial and temporal changes of urban agglomeration, industry cluster and port group coordination development in Bohai [D]. Liaoning Normal University. 2014(In Chinese) 